\title{
A randomized, open-label, multicenter, phase II study evaluating the efficacy and safety of BTH1677 (1,3-1,6 beta glucan; Imprime PGG) in combination with cetuximab and chemotherapy in patients with advanced non-small cell lung cancer
}

\author{
M. Thomas ${ }^{1}$ • P. Sadjadian ${ }^{2}$ - J. Kollmeier ${ }^{3} \cdot$ J. Lowe $^{4} \cdot$ P. Mattson ${ }^{4}$ - J. R. Trout ${ }^{5}$. \\ M. Gargano ${ }^{4}$ - M. L. Patchen ${ }^{4,6}$ • R. Walsh ${ }^{4}$ - M. Beliveau ${ }^{7}$ - J. F. Marier $^{7}$ • N. Bose ${ }^{4}$. \\ K. Gorden ${ }^{4} \cdot$ F. Schneller III ${ }^{8}$
}

Received: 16 February 2017 / Accepted: 1 March 2017 /Published online: 16 March 2017

(C) The Author(s) 2017. This article is published with open access at Springerlink.com

Summary Introduction BTH1677, a 1,3-1,6 beta-glucan immunomodulator, stimulates a coordinated anti-cancer immune response in combination with anti-tumor antibody therapies. This phase II study explored the efficacy, pharmacokinetics (PK), and safety of BTH1677 combined with cetuximab/

Key message This randomized Phase II study $(N=90)$ evaluated the addition of BTH1677, a novel pathogen-associated molecular pattern (PAMP) immunotherapy, to anti-tumor antibody and chemotherapy (cetuximab/carboplatin/paclitaxel) in previously untreated advancedstage non-small cell lung cancer (NSCLC) patients. Addition of BTH1677 improved overall response rates compared to antibody and chemotherapy alone.

\author{
M. L. Patchen \\ mpatchen@immunoresearch.com \\ M. Thomas \\ Michael.Thomas@med.uni-heidelberg.de \\ P. Sadjadian \\ Parvis.Sadjadian@muehlenkreiskliniken.de \\ J. Kollmeier \\ jens.kollmeier@helios-kliniken.de \\ J. Lowe \\ jlowe@biothera.com \\ P. Mattson \\ pmattson@biothera.com \\ J. R. Trout \\ rtrout@rci.rutgers.edu \\ M. Gargano \\ mgargano@biothera.com \\ R. Walsh \\ rwalsh@biothera.com
}

carboplatin/paclitaxel in untreated stage IIIB/IV non-small cell lung cancer (NSCLC) patients. Methods Patients were randomized 2:1 to the BTH1677 arm ( $N=60 ; \mathrm{BTH} 1677,4 \mathrm{mg} / \mathrm{kg}$, weekly; cetuximab, initial dose $400 \mathrm{mg} / \mathrm{m}^{2}$ and subsequent doses $250 \mathrm{mg} / \mathrm{m}^{2}$, weekly; carboplatin, $6 \mathrm{mg} / \mathrm{mL} / \mathrm{min}$ AUC
M. Beliveau

Martin.Beliveau@certara.com

J. F. Marier

jf.marier@certara.com

N. Bose

nbose@biothera.com

K. Gorden

kgorden@biothera.com

F. Schneller, III

ga69qaf@mytum.de

Internistische Onkologie der Thoraxtumoren, Thoraxklinik im Universitätsklinikum Heidelberg, Translational Lung Research Center Heidelberg (TLRC-H), Member of the German Center for Lung Research (DZL), Amalienstrasse 5,

69126 Heidelberg, Germany

2 Johannes Wesling Medical Center Minden, Clinic Hematology/ Oncology, Hans-Nolte-Str. 1, 32429 Minden, Germany

3 Lungenklinik Heckeshorn, HELIOS Klinikum Emil von Behring, Specialist Department 1: Clinic for Pneumology, Pneumology Oncology, Walterhöferstr.11, 14165 Berlin, Germany 
(area-under-the-curve) by Calvert formula, once each 3-week cycle [Q3W]); and paclitaxel, $200 \mathrm{mg} / \mathrm{m}^{2}, \mathrm{Q} 3 \mathrm{~W}$ ) or Control $\operatorname{arm}(N=30$; cetuximab/carboplatin/paclitaxel as above). Carboplatin/paclitaxel was discontinued after 4-6 cycles; patients who responded or remained stable received maintenance therapy with BTH1677/cetuximab (BTH1677 arm) or cetuximab (Control arm). Investigator and blinded central radiology reviews were conducted. Efficacy assessments included objective response rate (ORR; primary endpoint), disease control rate, duration of objective response, time-to-progression and overall survival (OS); safety was assessed by adverse events (AEs). Potential biomarker analysis for BTH1677 response was also conducted. Results Compared to control treatment, the addition of BTH1677 numerically increased ORR by both investigator $(47.8 \%$ vs $23.1 \% ; \mathrm{p}=0.0468)$ and central (36.6\% vs $23.1 \%$; $\mathrm{p}=0.2895$ ) reviews. No other endpoints differed between arms. PK was consistent with previous studies. BTH1677 was well tolerated, with AEs expected of the backbone therapy predominating. Biomarker-positive patients displayed better ORR and OS than negative patients. Conclusions BTH1677 combined with cetuximab/carboplatin/ paclitaxel was well tolerated and improved ORR as first-line treatment in patients with advanced NSCLC. Future patient selection by biomarker status may further improve efficacy

ClinicalTrials.gov Identifier: NCT00874848

Keywords Immunotherapy $\cdot \mathrm{NSCLC} \cdot$ Cetuximab · Biomarker · Beta glucan

\section{Introduction}

Lung cancer is the second most commonly diagnosed cancer in both men and women after prostate and breast cancer, respectively [1]. Approximately $85 \%$ of all lung cancers consist of non-small cell lung cancer (NSCLC) and patients usually present with locally advanced or metastatic disease at initial diagnosis [1]. For years, the first-line standard of care treatment for advanced NSCLC consisted of platinum-based combination chemotherapies [2, 3]. Although still a mainstay therapy for many NSCLC patients [4], advances in understanding the

$4 \quad$ Biothera Pharmaceuticals Inc., 3388 Mike Collins Drive, Suite A, Eagan, MN 55121, USA

5 Rutgers University, 82 Rittenhouse Circle, Newtown, PA 18940, USA

6 Present address: Immuno Research, Inc., 3388 Mike Collins Drive, Suite B, Eagan, MN 55121, USA

7 Pharsight/Certara, Pharsight - A Certara ${ }^{\mathrm{TM}}$ Company, 2000 Peel Street, Suite 570, Montréal, Québec H3A 2W5, Canada

8 Medical Clinic and Polyclinic, Klinikum rechts der Isar of Technical University Munich, Ismaninger Str. 22, 81675 Munich, Germany molecular pathways driving carcinogenesis (e.g., epidermal growth factor receptor [EGFR] gene mutations and anaplastic lymphoma kinase [ALK] translocations) led to development of targeted EGFR tyrosine kinase inhibitors and ALK-directed therapies that proved superior to chemotherapies for first-line management of advanced disease in select molecularly-defined patient subgroups harboring mutations sensitive to these therapies $[4,5]$. Several monoclonal antibody (MAb) therapies have also been developed for first-line treatment of advanced NSCLC [4], including bevacizumab, which targets vascular endothelial growth factor (VEGF) [6], cetuximab [7] and necitumumab [8], both of which target EGFR and, most recently, pembrolizumab, which targets the programmed death-1 (PD-1) immune checkpoint receptor on cytotoxic T-cells [9]. Additional MAbs approved for second-line therapy, but likely to soon be front-line therapy, include ramucirumab, an agent targeting VEGF receptor 2 (VEGFR2) [10], as well as the antiPD-1 and anti-programmed death ligand-1 (PD-L1) MAbs, nivolumab [11] and atezolizumab [12]. Unlike the other MAbs mentioned above, cetuximab ultimately never achieved regulatory approval for treatment of NSCLC. However, results of phase III NSCLC studies with cetuximab in combination with platinum doublet chemotherapy did show modest improvements in clinical efficacy endpoints [13, 14], which led to National Comprehensive Cancer Network guidelines recommending treatment of NSCLC with regimens containing cetuximab in select patients [4].

BTH1677 ( $\beta(1,6)$-[poly-(1,3)-D-glucopyranosyl]poly- $\beta$-(1,3)-D-glucopyranose; Imprime PGG; Biothera Pharmaceuticals Inc., Eagan, $\mathrm{MN}$ ), is a fungal-derived, water-soluble, 1,3-1,6 beta glucan. It is purified from the cell wall of a proprietary, non-recombinant, strain of the yeast Saccharomyces cerevisiae and consists purely of D-glucose molecules joined together via beta 1,3 and 1,6 linkages. Specifically, it consists of a backbone of 1,3 linked glucose residues with periodic branches linked to the backbone in a 1,6 configuration. Similar to the backbone, the side chains also contain multiple 1,3-linked glucose residues. No beta glucans have been approved for clinical use in the United States. However, in China and Japan, two fungal mushroomderived 1,3-1,6 beta glucans (lentinan and schizophyllan) have been approved. The chemical structure of BTH1677 is different from that of mushroom-derived beta glucans which have a higher branching frequency and side chains that consist of only single glucose residues [15-17].

BTH1677 functions as a pathogen-associated molecular pattern (PAMP) molecule to stimulate a coordinated innate and adaptive anti-cancer immune response in combination with anti-tumor antibody therapies. When BTH1677 enters the blood, it is bound by endogenous plasma anti-beta glucan antibodies (ABA) resulting in complement activation and opsonization with complement protein $\mathrm{iC} 3 \mathrm{~b}$ [18, 19]. The BTH1677/ABA/iC3b complex initially binds to innate 
immune effector cells through complement receptor 3 and Fc gamma receptor IIA (Fc $\gamma$ IIA) $[18,19]$, activating innate immune cell function and enabling direct killing of antibodytargeted tumor cells [18]. BTH1677 also enables reeducation of the tumor microenvironment, shifting the normally suppressive M2-state macrophages to a more M1 (tumor attack) state [20, 21], and promoting depletion and/or maturation of myeloid-derived suppressor cells in the tumor microenvironment [22]. BTH1677 treatment additionally activates antigenpresenting cells, driving co-stimulatory marker expression on macrophages and dendritic cells, as well as dendritic cell maturation, CD4 and CD8 T-cell expansion, and production of key anti-tumor cytokines (e.g., interferon gamma) [21, 23-26]. In murine syngeneic and xenogeneic tumor models, the administration of BTH1677 with various tumor-targeting monoclonal antibodies has resulted in greater suppression of tumor growth and longer survival than with either agent alone [27-29]. One of these studies [28] specifically evaluated BTH1677 and cetuximab in a lung cancer model. Similar effects have been observed with BTH1677 combined with anti-angiogenic antibodies (anti-VEGF and anti-VEGFR2) $[22,30,31]$ and checkpoint inhibitor antibodies [32, 33].

Clinically, in healthy subjects, BTH1677 was well tolerated after single doses up to $6 \mathrm{mg} / \mathrm{kg}$ and after 7 daily doses up to $4 \mathrm{mg} / \mathrm{kg}$ and pharmacokinetic (PK) parameters demonstrated linearity with dose [34]. Additionally, BTH1677 in combination with cetuximab, with or without irinotecan, was well tolerated with promising evidence of efficacy in a phase Ib/II study in patients with recurrent or progressive metastatic colorectal cancer (mCRC) [35-37].

Based on the preclinical efficacy observed in vivo in murine lung cancer models with BTH1677 combined with either cetuximab [28] or bevacizumab [31], parallel studies were designed to evaluate these BTH1677 combinations in NSCLC patients. Here we report results of the randomized, open-label, multicenter, phase II study (NCT00874848) designed to evaluate the antitumor activity, safety, and PK profile of BTH1677 when combined with cetuximab and concomitant carboplatin and paclitaxel therapy in patients with previously untreated, advanced NSCLC. Exploratory evaluation of the potential use of baseline ABA levels as a measure of a patient's ability to respond to BTH1677 is also presented. At the time this study was initiated, cetuximab was undergoing regulatory review for first-line use in latestage NSCLC patients, with approval anticipated. This anticipation, along with our preclinical and clinical mCRC data demonstrating enhanced antitumor effects with BTH1677 combined with cetuximab therapy prompted us to evaluate this combination in NSCLC. Although cetuximab was ultimately not approved and is not currently a standard therapy for NSCLC, the results of this study nevertheless support the concept of improved efficacy with the addition of BTH1677 to antitumor antibody therapy.

\section{Materials and methods}

\section{Study objectives}

The primary objective was to evaluate the objective response rate (ORR; complete response $[\mathrm{CR}]+$ partial response $[\mathrm{PR}]$ ) in each treatment arm. Secondary objectives included assessment of best response rate (CR, PR, and stable disease [SD] rates), disease control rate (DCR; $\mathrm{CR}+\mathrm{PR}+\mathrm{SD})$, duration of objective tumor response (DOR), time-to-progression (TTP), and overall survival (OS) in each treatment arm. Safety within each arm and the PK profile of BTH1677 (BTH1677 arm only) were also evaluated. Exploratory analysis evaluated correlations between baseline $\mathrm{ABA}$ levels and clinical responses.

\section{Patient eligibility}

Patients, 18 to 75 years of age, provided written informed consent, and had histologically or cytologically confirmed stage IIIB or IV NSCLC according to American Joint Committee on Cancer (AJCC) Staging v6; measurable disease as defined by Response Evaluation Criteria in Solid Tumors (RECIST) v1.0; Eastern Cooperative Oncology Group (ECOG) performance status (PS) 0 or 1 ; life expectancy of $>3$ months; adequate hematologic, renal, and hepatic function; and use of an effective contraceptive.

Exclusion criteria included prior systemic chemotherapy for lung cancer; previous radiation therapy to $>30 \%$ of active bone marrow or any radiation therapy within 3 weeks of study Day 1 ; central nervous system metastases; uncontrolled hypertension; peripheral neuropathy $\geq$ Grade 2 ; fever $>38.5^{\circ} \mathrm{C}$ within 3 days of Day 1; active yeast infection; human immunodeficiency virus/acquired immune deficiency syndrome, hepatitis $\mathrm{B}$, or hepatitis $\mathrm{C}$; connective tissue or autoimmune disease; previous organ or progenitor/stem cell transplant; history of myocardial infarction or any other unstable or uncontrolled heart disease; second malignancy within the previous 5 years (other than basal cell carcinoma, cervical intra-epithelial neoplasm, or curatively treated prostate cancer); known hypersensitivity to baker's yeast, murine proteins, or Cremophor® EL; previous exposure to cetuximab or BTH1677; or investigational therapy within 30 days prior to Day 1 . Females were also excluded if they were pregnant or breastfeeding.

\section{Study design and treatment plan}

This randomized, open-label, multicenter phase II study was performed at sites in Germany and the United States and was conducted in full accordance with the Good Clinical Practice: Consolidated Guideline approved by the International Conference on Harmonisation and all other applicable national and local laws/regulations. All study materials were 
approved by the governing ethics committee or institutional review board at each site.

The study tested the null hypothesis that the true ORR was $\leq 30 \%$ vs the alternative hypothesis that the true ORR in the BTH1677 arm was at least 50\%. Based on the Simon 2-stage optimal flexible design [38] it was determined that 60 patients in the BTH1677 arm would provide $90 \%$ power for the hypotheses testing at an alpha level of 5\%. With 2:1 randomization, a sample size of 30 patients was determined for the Control arm. The first stage enrolled 15 and 7 evaluable patients in the BTH1677 and Control arms, respectively. Criteria for progression to the second stage were met and enrollment continued to the full planned patient numbers.

Patients were dosed in 3-week cycles. On Days 1, 8, and 15 of each cycle, patients in the BTH1677 arm were administered $4 \mathrm{mg} / \mathrm{kg}$ of BTH1677 (intravenous [IV] over 2 to $4 \mathrm{~h}$, depending on patient weight and total dose administered). On these same days, cetuximab was administered to all patients in both arms (initial IV loading dose of $400 \mathrm{mg} / \mathrm{m}^{2}$ over $120 \mathrm{~min}$ and subsequent IV doses at $250 \mathrm{mg} / \mathrm{m}^{2}$ over $60 \mathrm{~min}$ ); in the BTH1677 arm, cetuximab was administered after BTH1677. On Day 2 of each cycle, IV carboplatin (dosed according to Calvert formula area under the curve [AUC] of $6 \mathrm{mg} / \mathrm{mL} / \mathrm{min}$ over $30 \mathrm{~min}$ ) and IV paclitaxel $\left(200 \mathrm{mg} / \mathrm{m}^{2}\right.$ over $\left.3 \mathrm{~h}\right)$ were administered to all patients. Prior to each BTH1677 dosing, all patients were to receive low-dose corticosteroids and a histamine-1 antagonist (e.g., $4 \mathrm{mg}$ of dexamethasone orally [PO] and $50 \mathrm{mg}$ of diphenhydramine IV). On Day 2 of each cycle, all patients were premedicated with the local clinic's regimen of corticosteroids and antihistamines prior to carboplatin and paclitaxel therapy. Premedication for the Control arm patients was performed according to local clinical practice for cetuximab.

Carboplatin and paclitaxel administration continued for at least four cycles, but could continue for up to six cycles at the investigator's discretion. Following completion of their sixth dosing cycle, patients who experienced a response (CR or PR) or had remained stable (SD) were eligible to continue on maintenance therapy receiving BTH1677 and cetuximab (BTH1677 arm) or cetuximab alone (Control arm).

\section{Study assessments}

Safety and tolerability were assessed by adverse events (AEs; National Cancer Institute Common Terminology for Adverse Events [CTCAE] v3.0), physical examinations, and laboratory tests.

Tumor response assessments were based on computed tomography (CT) scans performed every other cycle (i.e., at 6week intervals). Both investigator and blinded central independent radiology reviews were performed. Tumor response was assessed using a modified RECIST v1.0 criteria in which an initial response did not require a repeat assessment for confirmation. All other RECIST v1.0 criteria remained unmodified.
ABA assessments were performed by prototype enzymelinked immunosorbent assays (ELISAs) developed at Biothera Pharmaceuticals Inc. to detect serum IgG and IgM ABA $[18,39]$. A commercially available pooled human serum was assigned an arbitrary value of $\operatorname{IgG}$ or IgM ABA units per milliliter (relative antibody units $/ \mathrm{mL}$; RAU $/ \mathrm{mL}$ ) and run as a standard curve in each assay to determine test sample ABA levels. A previous study had shown correlations between ABA levels and the ability of BTH1677 to activate complement (as measured by C5a production), bind to neutrophils, induce neutrophil surface expression of complement receptor 3 (CR3), modulate neutrophil activation markers (CD88 and CD62), and induce production of interleukin-8 (IL-8) when incubated with whole blood samples obtained from healthy subjects $[18,39]$. These effects were consistently seen in blood with ABA levels above the thresholds of 235 IgG RAU/mL or $330 \mathrm{IgM} \mathrm{RAU} / \mathrm{mL}$, but were not seen, or seen at much lower levels, in blood with ABA levels below these thresholds $[18,39]$. Subjects with ABA levels above the thresholds were identified as biomarker positive and those below the thresholds were identified as biomarker negative. These prospectively defined thresholds from the healthy volunteer study were applied to the NSCLC patient samples to determine patient ABA biomarker status (ie, positive vs negative). At the time of this NSCLC study, the importance of $\mathrm{ABA}$ in the mechanism of action of BTH1677 was not known and the protocol did not include collection of samples for ABA analysis. However, it was possible to perform ABA determinations from serum samples remaining from baseline (pre-dosing) PK samples. Since PK samples were only collected from patients in the BTH1677 arm, biomarker analyses could be performed only in these patients. Correlation of ABA status and clinical responses was performed in posthoc hypotheses-generating analyses.

\section{Pharmacokinetics}

PK assessments for BTH1677 were based on post-dosing blood samples collected on Day 1 of Cycles 1 and 3 . Samples for BTH1677 trough level assessments were also obtained before dosing on all other weeks of Cycles 1 and 2 . Serum BTH1677 levels were measured by a beta-glucan specific ELISA developed at Biothera Pharmaceuticals Inc. which had a lower limit of detection of $1.2 \mathrm{ng} / \mathrm{mL}$ and a limit of quantitation of $4.7 \mathrm{ng} / \mathrm{mL}$. Serum PK parameters of BTH1677 were calculated using noncompartmental analysis (NCA) with NCA model 202 (constant infusion dose input) in WinNonlin ${ }^{\circledR}$ v5.2.

\section{Statistical analysis}

The analysis populations for investigator and central radiology tumor assessments, safety and survival analyses, 
and PK analyses are shown by treatment arm in Fig. 1. The analysis populations for tumor assessments (primary efficacy populations) were comprised of all randomized patients who received any amount of cetuximab, carboplatin, or paclitaxel, with or without BTH1677, and who had an evaluable baseline CT scan assessment and at least one evaluable post-baseline CT scan assessment. The investigator and central radiology review populations were not identical due to separate assessments of the above criteria by the two review groups. The safety and survival populations were comprised of all randomized patients who received any amount of study drugs. The PK population was comprised of all patients who had at least $75 \%$ of the PK measurements available for any particular treatment cycle data set.

Efficacy and safety measures are displayed by treatment arm. Categorical data are presented by $n$ and $\%$ for each category and continuous data are presented by mean and standard deviation (SD). Kaplan-Meier estimates were utilized for time-to-event analyses and, where appropriate, $95 \%$ confidence intervals (CI) are provided. Comparisons between treatment arms were performed at a 0.05 level of significance. AEs are summarized by system organ class using the Medical Dictionary for Regulatory Activities v15.0.

\section{Results}

\section{Patient disposition}

Between August 2009 and November 2012, 90 patients with NSCLC were randomized 2:1 to the BTH1677 arm or the Control arm. As shown in Fig. 1, a total of 88 patients (BTH1677, $N=59$; Control, $N=29$ ) were treated and included in the safety and survival analyses. The investigator radiology review population included 46 patients in the BTH1677 arm and 26 patients in the Control arm. The central radiology review population included 41 patients in the BTH1677 arm and 26 patients in the Control arm. The primary reason for patient exclusion from either review population was the absence of baseline or post-baseline CT scan data. The primary reason for treatment discontinuation in each arm was tumor progression (BTH1677, 63.3\%; Control, 60.0\%).

Patient demographics and disease characteristics at baseline are shown in Table 1. The BTH1677 and Control arms were generally similar with regard to race, age, ECOG PS, disease stage at initial diagnosis, and time from initial tumor diagnosis. There were more males in the BTH1677 arm (74.6\%) than in the Control arm (58.6\%) and the percentage of patients who received prior radiotherapy was higher in the Control arm (10.3\%) than in the BTH1677 arm (0\%).

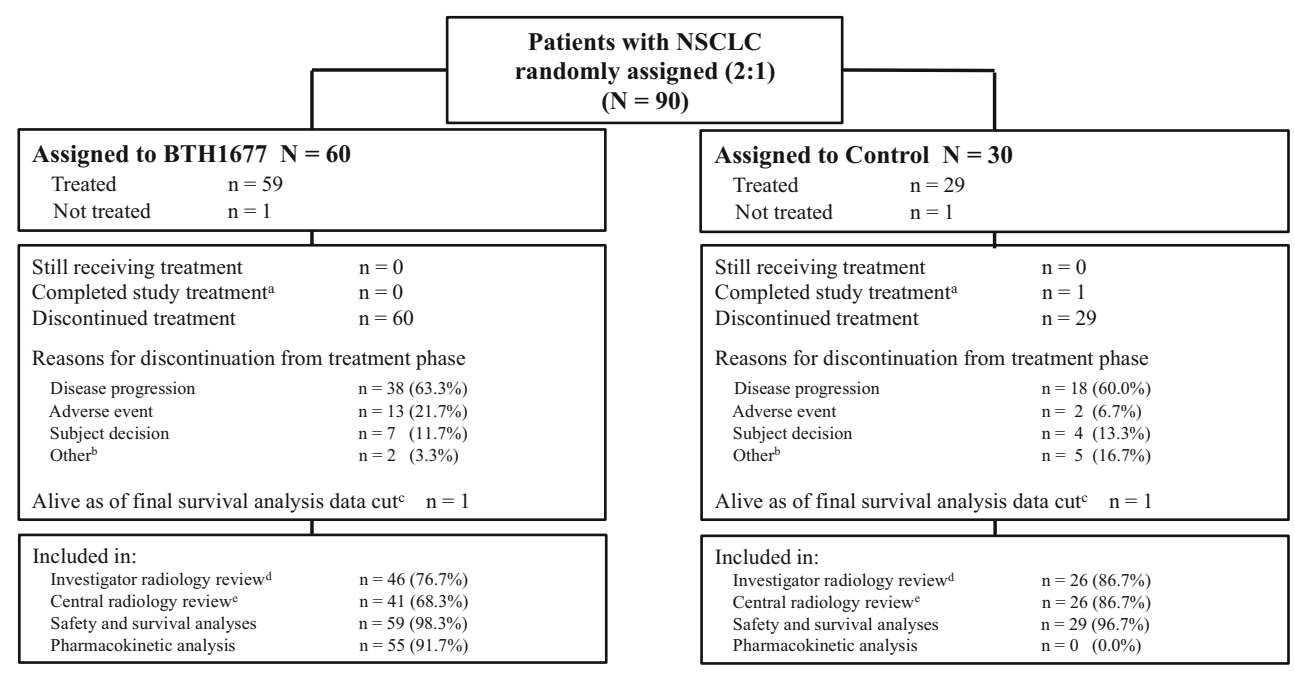

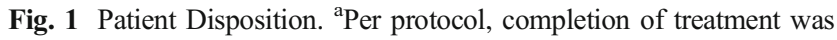
defined as patients completing 18 cycles of treatment without progressive disease; ${ }^{\mathrm{b}}$ For the BTH1677 arm these included lost to follow-up $(n=1)$ and never treated $(n=1)$; For the Control arm these included investigator decision $(n=2)$, noncompliance $(n=2)$, and never treated $(n=1)$; ${ }^{\mathbf{c}}$ Final survival analysis was performed approximately 4 years after the randomization date of the last patient enrolled into study; ${ }^{\mathrm{d}}$ Reasons for exclusion from efficacy analyses related to investigator radiology review in the BTH1677 arm were no evaluable post-baseline CT scan ( $n=14$; none of these patients had a best response of disease progression ie, clinical progression, reported by the investigator); in the Control arm reasons were no evaluable baseline and/or post-baseline CT scan $(n=4$; none of these patients had a best response of disease progression (ie, clinical progression) reported by the investigator); ${ }^{\mathrm{e}}$ Reasons for exclusion from efficacy analyses related to central radiology review in the BTH1677 arm were no evaluable baseline and/or post-baseline CT scan $(n=19$; one of these patients had a best response of disease progression ie, clinical progression, reported by the investigator); in the Control arm reasons were no evaluable baseline and/or post-baseline CT $\operatorname{scan}(n=4$; none of these patients had a best response of disease progression (ie, clinical progression) reported by the investigator) 
Table 1 Patient demographics and disease characteristics at baseline (Safety population)

\begin{tabular}{|c|c|c|}
\hline Characteristic & BTH1677 $(N=59)$ & Control $(N=29)$ \\
\hline \multicolumn{3}{|l|}{ Age (years) } \\
\hline Median (range) & $58(38,78)$ & $65(41,71)$ \\
\hline \multicolumn{3}{|l|}{ Sex, n $(\%)$} \\
\hline Male & $44(74.6)$ & $17(58.6)$ \\
\hline Female & $15(25.4)$ & $12(41.4)$ \\
\hline \multicolumn{3}{|l|}{ Race, n (\%) } \\
\hline White & $56(94.9)$ & $29(100.0)$ \\
\hline Black & $2(3.4)$ & 0 \\
\hline Other & $1(1.7)$ & 0 \\
\hline \multicolumn{3}{|c|}{ ECOG performance status, n (\%) } \\
\hline 0 & $20(33.9)$ & $10(34.5)$ \\
\hline 1 & $38(64.4)$ & $18(62.1)$ \\
\hline Missing & $1(1.7)$ & $1(3.4)$ \\
\hline \multicolumn{3}{|c|}{ Disease stage at initial diagnosis, $\mathrm{n}(\%)^{\mathrm{a}}$} \\
\hline IIIB & $3(5.1)$ & $4(13.8)$ \\
\hline IV & $56(94.9)$ & $25(86.2)$ \\
\hline \multicolumn{3}{|c|}{ Histology type, n (\%) } \\
\hline Squamous & $16(27.1)$ & $11(37.9)$ \\
\hline Non-squamous & $42(71.2)$ & $18(62.1)$ \\
\hline Missing & $1(1.7)$ & 0 \\
\hline \multicolumn{3}{|c|}{ Time from initial tumor diagnosis (months) ${ }^{b}$} \\
\hline Median (range) & $0.7(0.2,6.5)$ & $0.5(0,8.2)^{\mathrm{c}}$ \\
\hline \multicolumn{3}{|c|}{ Prior cancer treatment, $\mathrm{n}(\%)$} \\
\hline Radiotherapy & 0 & $3(10.3)$ \\
\hline Surgery & $23(39.0)$ & $13(44.8)$ \\
\hline Chemotherapy $^{\mathrm{d}}$ & $1(1.7)$ & $1(3.4)$ \\
\hline
\end{tabular}

ECOG Eastern Cooperative Oncology Group

${ }^{\text {a }}$ At the time this study was performed, malignant pleural or pericardial effusions were considered Stage IIIB, however as of the 7th edition of the Cancer Staging Manual of the American Joint Committee on Cancer this would be considered Stage IV (ie, by current staging, all patients were Stage IV)

${ }^{\mathrm{b}}$ Time from initial tumor diagnosis (months) = screening visit - initial tumor diagnosis date) $/ 30$

${ }^{\mathrm{c}}$ Based on $N=28$

${ }^{\mathrm{d}}$ One patient in the BTH1677 arm received prior chemotherapy for NonHodgkin's lymphoma and 1 patient in the Control arm received radiotherapy that was inadvertently categorized as chemotherapy

\section{Efficacy}

Tumor-associated assessments Tumor response assessments are shown in Table 2. For both investigator and central radiology reviews, ORR for the BTH1677 arm was numerically increased; however, statistical significance was seen only in the investigator review. Investigator review ORR for the BTH1677 and Control arms, respectively, was 47.8\% (95\% CI: $32.9,63.1)$ and $23.1 \%$ (95\% CI: 9.0, 43.6) $(p=0.0468)$ and central review ORR for the BTH1677 and Control arms, respectively, was $36.6 \%$ (95\% CI: $22.1,53.1$ ) and $23.1 \%$ (95\% CI: 9.0, 43.6) $(p=0.2895)$. In both reviews, all responses were PR. Taking into account the SD rates, DCRs were high in both reviews and did not statistically differ between treatment arms in either review (investigator BTH1677 78.3\% [95\% CI 63.6, 89.1] vs Control 76.9\% [95\% CI 56.4, 91.0], $p=1.000$; central BTH1677 85.4\% [95\% CI 70.8, 94.4] vs Control $80.8 \%$ [95\% CI 60.6, 93.4], $p=0.7385$ ). The DOR and TTP also did not differ between treatment arms in either review. DOR and TTP for the BTH1677 arm vs Control arm by the investigator review were 3.8 (95\% CI: $2.8,4.2)$ vs 4.7 (95\% CI: 1.4, not estimable) months and 4.3 (95\% CI: 3.6, 5.6) vs 4.4 (95\% CI: 3.2, 5.9) months, respectively, and by the central review were 4.4 (95\% CI: $2.8,6.5)$ vs 4.1 (95\% CI: 1.4 , 5.4) months and 6.4 (95\% CI: 4.3, 8.3) vs 6.0 (95\% CI: 4.3, 7.1) months, respectively.

Overall survival The OS Kaplan Meier curves for the BTH1677 and Control arms are shown in Fig. 2a. The median OS of patients in the BTH1677 arm was 10.3 months $(95 \%$ CI: 8.6, 15.1) compared with 12.4 months (95\% CI: 9.3, 17.4) in the Control arm. No statistical significance in OS was observed between arms (hazard ratio 1.14; 95\% CI: 0.67, 2.00; $p=0.6288)$.

Exploratory analyses by ABA biomarker status of the 59 BTH1677 patients in the study, $22(37.3 \%)$ were determined to be ABA biomarker positive and $37(62.7 \%)$ to be ABA biomarker negative. In the radiology review populations, there were 15 biomarker-positive and 31 biomarker-negative patients in the investigator review population and 13 biomarker-positive and 28 biomarker-negative patients in the central review population. Based on the investigator review, compared to ORRs of $23.1 \%$ in the Control arm and $47.8 \%$ in the BTH1677 arm, ORR in the biomarker-negative BTH1677 patients was $38.7 \%$ (95\% CI: $21.8,57.8 ; p=0.2592$ vs Control) and $66.7 \%$ in the biomarker-positive BTH1677 patients (95\% CI: $38.4,88.2 ; p=0.0088$ vs Control; $p=0.1162$ vs BTH1677 biomarker negative). However, based on central review, compared to ORRs of $23.1 \%$ in the Control arm and $36.6 \%$ in the BTH1677 arm, ORR in the biomarker-negative BTH1677 patients was $35.7 \%$ (95\% CI: 18.6, 55.9; $p=0.3791$ vs Control) and $38.5 \%$ in the biomarker-positive BTH1677 patients (95\% CI: 13.9, 68.4; $p=0.4528$ vs Control; $p=1.000$ vs BTH1677 biomarker negative). Survival favored BTH1677 biomarker-positive patients (Fig. 2a). Compared to median OS of 12.4 months in the Control arm and 10.3 months in the BTH1677 arm, median OS in the biomarker-negative BTH1677 patients was 9.2 months (vs Control, HR 1.55 [95\% CI: $0.85,2.81] ; p=0.1507)$ and 17.0 months in the biomarkerpositive BTH1677 patients (vs Control HR 0.79 [95\% CI: $0.39,1.58] ; p=0.4964$; vs biomarker negative, HR 0.48 [95\% CI: $0.24,0.95] ; p=0.0327$ ). 


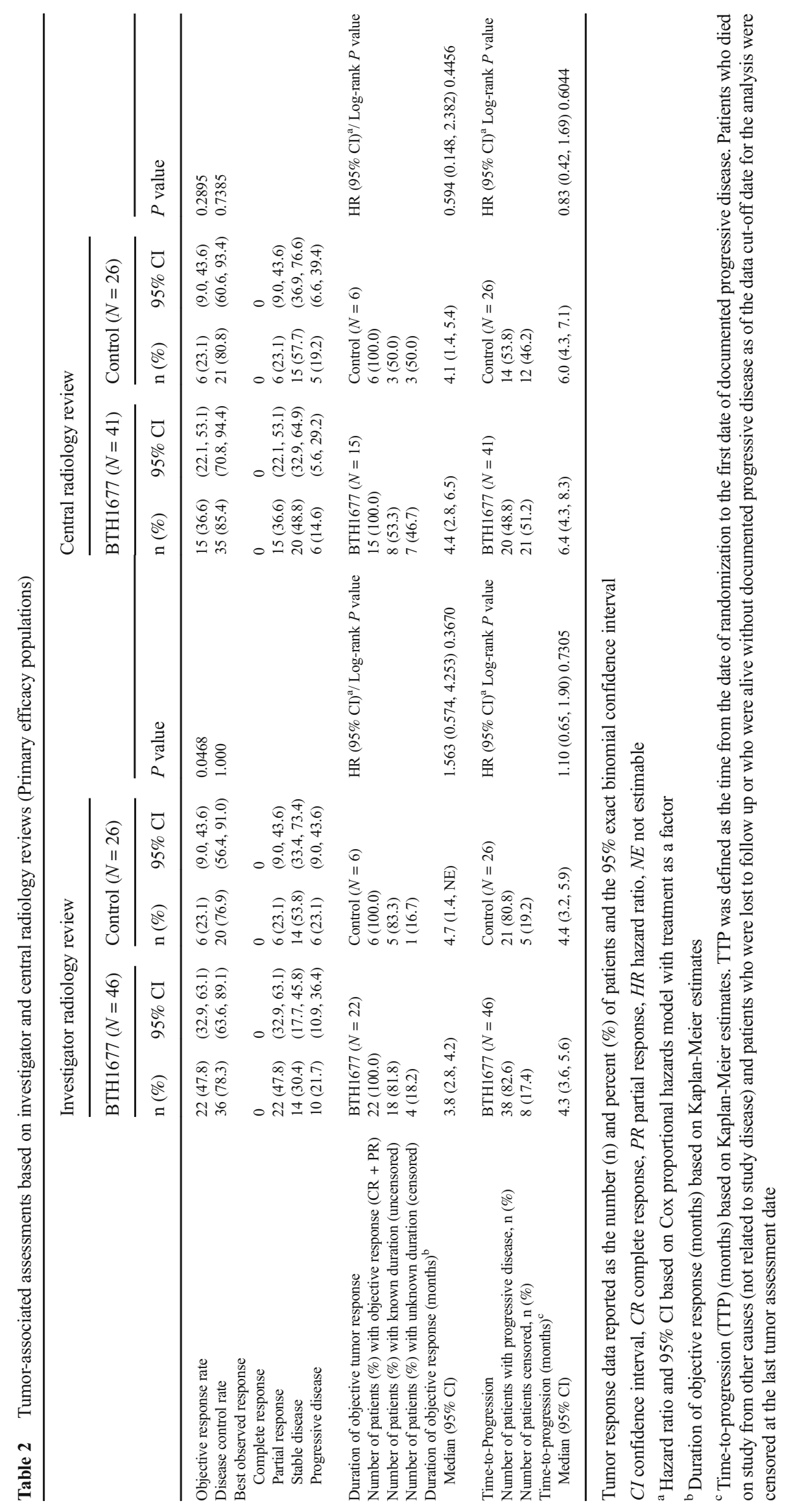


Fig. 2 Overall Survival. The Kaplan-Meier overall survival curves from patients in the safety population are shown by treatment arm (Fig. 2a) and by anti-beta-glucan antibody biomarker status (Fig. 2b). HR, hazard ratio; CI, confidence interval
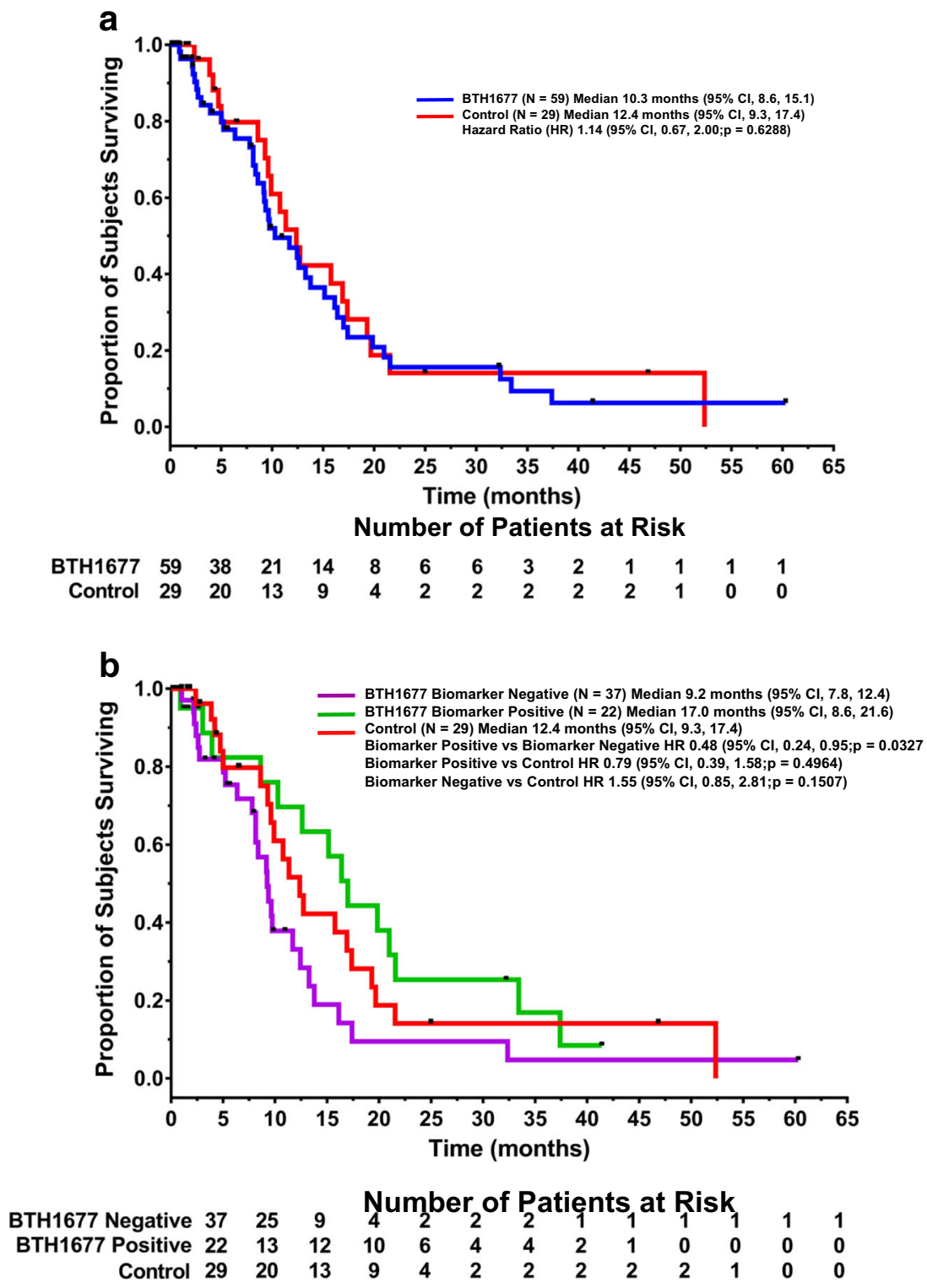

\section{Safety}

All patients receiving any treatment $(\mathrm{BTH} 1677 N=59$; Control $N=29$ ) were included in the safety population and all of these patients experienced at least $1 \mathrm{AE}$ (Table 3). In the BTH1677 arm, $44.1 \%$ and $28.8 \%$ of the patients were assessed as having AEs that were probably or possibly related to BTH1677, respectively. Grade 3 or Grade 4 AEs occurred at a slightly lower incidence in the BTH1677 arm vs Control arm (78.0\% vs $86.2 \%$ ). However, serious adverse events (SAEs) and AEs leading to treatment discontinuation occurred at a higher incidence in the BTH1677 arm vs the Control arm $(62.7 \%$ vs $41.4 \%$ and $22.0 \%$ vs $6.9 \%$, respectively). SAEs occurring in more than one patient in the Control arm were neutropenia, diarrhea, and pulmonary embolism (each occurring in 2 patients [6.9\%]). SAEs occurring in more than one patient in the
BTH1677 arm were pleural effusion (6 patients [10.2\%]), pulmonary embolism (5 patients [8.5\%]), and dyspnea and hemoptysis (each occurring in 2 patients [3.4\%]). AEs leading to discontinuation in the Control arm were acute myocardial infarction and dermatitis (each occurring in 1 patient [3.4\%]) and in the BTH1677 arm were atrial flutter, cardiac failure acute, tachyarrhythmia, chills, anaphylactic shock, paresthesia, bronchospasm, hemoptysis, pleural effusion, pulmonary embolism, and pulmonary hemorrhage (each occurring in 1 patient $[1.7 \%$ each]) and hypersensitivity (occurring in 2 patients [3.4\%]).

All AEs occurring in $\geq 10 \%$ of patients in either the BTH1677 arm or Control arm are presented in Table 4. As expected from the backbone therapy of cetuximab, carboplatin and paclitaxel, skin, hematological, gastrointestinal and neurological AEs occurred frequently in both groups. The difference in specific $\mathrm{AE}$ incidence between treatment groups was 
Table 3 Overview of safety outcomes

\begin{tabular}{lll}
\hline Adverse Events (AEs), n $(\%)$ & BTH1677 $(N=59)$ & Control $(N=29)$ \\
\hline Any AE & $59(100.0)$ & $29(100.0)$ \\
NCI/CTCAE Grade 3 or 4 AEs & $46(78.0)$ & $25(86.2)$ \\
Serious AEs & $37(62.7)$ & $12(41.4)$ \\
BTH1677-related AEs & & NA \\
$\quad$ Probably related & $26(44.1)$ & NA \\
$\quad$ Possibly related & $17(28.8)$ & $2(6.9)$ \\
AEs leading to treatment discontinuation & $13(22.0)$ & \\
\hline
\end{tabular}

$A E$ adverse events, NCI/CTCAE National Cancer Institute Common Terminology Criteria for Adverse Events, $N A$ not applicable generally less than $10 \%$, with the exception of neutropenia, anemia, constipation, pyrexia, white blood cell count decreased, paresthesia, peripheral sensory neuropathy, cough, dyspnea, dysphonia, and rash, all of which occurred at $\mathrm{a} \geq 10 \%$ lower incidence in the BTH1677 arm vs the Control arm. Only $1 \mathrm{AE}$, skin fissures, occurred at $\geq 10 \%$ higher incidence in the BTH1677 arm vs the Control arm (18.6\% vs 6.9\%).

For the AEs occurring in $\geq 10 \%$ of patients, the incidence occurring at Grade 3 or Grade 4 is also shown in Table 4. The most common Grade 3 or Grade 4 AEs were hematological, of which a lower incidence was again seen in the BTH1677 arm vs the Control arm. Grade 3 or Grade 4 AEs seen exclusively in the BTH1677 arm were abdominal pain (3.4\%), fatigue $(6.8 \%)$, hypersensitivity $(3.4 \%)$, decreased hemoglobin $(6.8 \%)$, hypomagnesemia $(1.7 \%)$, pain in extremity $(1.7 \%)$, dysphonia (1.7\%), and pleural effusion (5.1\%). Grade 3 or Grade 4 AEs seen exclusively in the Control arm were nausea $(3.4 \%)$, diarrhea $(10.3 \%)$, mucosal inflammation $(3.4 \%)$, chest pain $(3.4 \%)$, pyrexia $(3.4 \%)$, asthenia $(3.4 \%)$, white blood cell count decreased (6.9\%), myalgia (3.4\%), and back pain $(3.4 \%)$. Instances of these events were low, generally occurring in only 1-2 patients. Evaluation of all AEs and Grade 3 or Grade 4 AEs by ABA biomarker status did not demonstrate differences between groups (data not shown).

Seven deaths ( 6 in the BTH1677 arm; 1 in the Control arm) were reported in the treatment phase or within 30 days of the last dose of study medication. Four of the six deaths in the BTH1677 arm were due to disease progression; the other two were due to neutropenia/sepsis/acute renal failure (possibly related to carboplatin and paclitaxel and unlikely related to BTH1677 and cetuximab) and pleural effusion caused by previously broken ribs (unlikely related to any treatment). The one death that occurred in the Control arm was due to disease progression.

\section{BTH1677 pharmacokinetics}

Overall, serum BTH1677 concentration-time profiles were well characterized and consistent in Cycle 1 and Cycle 3. All serum concentrations of BTH1677 were above the limit of quantitation $(4.7 \mathrm{ng} / \mathrm{mL})$ in both cycles and mean concentrations declined in a multi-exponential manner over time (data not shown). Table 5 summarizes the BTH1677 PK parameters from Cycle 1/Day $1(N=52)$ and Cycle 3/Day 1 $(N=36)$. The difference between the $N$ for the two cycles largely reflected patients discontinuing the study between Cycle 1 and Cycle 3. Geometric mean $\mathrm{AUC}_{0-24}$ values of BTH1677 were similar in Cycle $1(362 \mu \mathrm{g} \bullet \mathrm{hr} . / \mathrm{mL})$ and Cycle 3 (396 $\mu \mathrm{g} \bullet \mathrm{hr} . / \mathrm{mL})$. Geometric mean $\mathrm{C}_{\max }$ values $(44.3 \mu \mathrm{g} / \mathrm{mL}$ and $47.8 \mu \mathrm{g} / \mathrm{mL})$ and median $\mathrm{t}_{\max }$ values $(2.25 \mathrm{~h}$ and $2.40 \mathrm{~h})$ were also similar in both Cycle 1 and Cycle 3, respectively. Cross-cycle comparison of all other PK parameters $\left(\mathrm{AUC}_{0-\text { last }}, \mathrm{AUC}_{0-\infty}, \mathrm{CL}\right.$, and $\mathrm{t}_{1 / 2}$ ) should be interpreted with caution since there was a difference in the blood sampling interval between cycles (Cycle 1: $168 \mathrm{~h}$ and Cycle 3: $24 \mathrm{~h})$. The apparent shorter elimination half-life of BTH1677 in Cycle 3 relative to Cycle 1 (8.46 h and 19.1 h, respectively) is likely to be representative of a distribution phase rather than an elimination phase. Overall, the data suggest that exposure to BTH1677 was consistent in both cycles. BTH1677 levels assessed weekly before dosing through Day 1 Cycle 3, revealed no meaningful accumulation of BTH1677 with weekly dosing. Mean clearance of BTH1677 on Day 1 of Cycles 1 and $3(0.477 \mathrm{~L} / \mathrm{h}$ and $0.696 \mathrm{~L} / \mathrm{h}$, respectively) were consistent with that reported in healthy subjects $(0.441 \mathrm{~L} / \mathrm{h}-$ 0.619 L/h) [34].

Exploratory analyses of PK parameters by biomarker status revealed no difference between biomarker-positive vs biomarker-negative patients (data not shown).

\section{Discussion}

BTH1677 is a novel PAMP being developed for the treatment of cancer in combination with tumor-targeted antibodies, as well as anti-angiogenic and checkpoint inhibitor antibodies. A previous phase $\mathrm{Ib} / \mathrm{II}$ study in second- to third-line $\mathrm{mCRC}$ patients evaluated BTH1677 combined with cetuximab and showed good tolerability with promising efficacy [34-37]. This randomized, open-label, phase II study demonstrated that 
Table 4 Any grade adverse events occurring in $\geq 10 \%$ of patients and the incidence of these that were grade 3 or 4 within indicated categories (Safety population)

\begin{tabular}{|c|c|c|c|c|}
\hline \multirow[b]{2}{*}{ Adverse Events (AEs), n (\%) } & \multicolumn{2}{|c|}{ BTH1677 $(N=59)$} & \multicolumn{2}{|c|}{ Control $(N=29)$} \\
\hline & All AEs & Grade 3 or Grade 4 AEs & All AEs & Grade 3 or Grade 4 AEs \\
\hline Number of patients with at least $1 \mathrm{AE}$ & $59(100.0)$ & $46(78.0)$ & $29(100.0)$ & $25(86.2)$ \\
\hline \multicolumn{5}{|l|}{ Blood and lymphatic system disorders } \\
\hline Neutropenia & $22(37.3)$ & $19(32.2)$ & $15(51.7)$ & $14(48.3)$ \\
\hline Leukopenia & $13(22.0)$ & $9(15.3)$ & $9(31.0)$ & $9(31.0)$ \\
\hline Anemia & $5(8.5)$ & $3(5.1)$ & $8(27.6)$ & $2(6.9)$ \\
\hline Thrombocytopenia & $6(10.2)$ & $2(3.4)$ & $5(17.2)$ & $2(6.9)$ \\
\hline \multicolumn{5}{|l|}{ Gastrointestinal disorders } \\
\hline Nausea & $25(42.4)$ & 0 & $12(41.4)$ & $1(3.4)$ \\
\hline Diarrhea & $24(40.7)$ & 0 & $9(31.0)$ & $3(10.3)$ \\
\hline Constipation & $11(18.6)$ & 0 & $10(34.5)$ & 0 \\
\hline Vomiting & $11(18.6)$ & 0 & $5(17.2)$ & 0 \\
\hline Abdominal pain & $6(10.2)$ & $2(3.4)$ & $4(13.8)$ & 0 \\
\hline Stomatitis & $4(6.8)$ & 0 & $4(13.8)$ & 0 \\
\hline \multicolumn{5}{|c|}{ General disorders and administration site conditions } \\
\hline Fatigue & $30(50.8)$ & $4(6.8)$ & $17(58.6)$ & 0 \\
\hline Mucosal inflammation & $13(22.0)$ & 0 & $6(20.7)$ & $1(3.4)$ \\
\hline Chest pain & $10(16.9)$ & 0 & $5(17.2)$ & $1(3.4)$ \\
\hline Chills & $9(15.3)$ & $2(3.4)$ & $4(13.8)$ & $1(3.4)$ \\
\hline Pyrexia & $4(6.8)$ & 0 & $8(27.6)$ & $1(3.4)$ \\
\hline Edema peripheral & $5(8.5)$ & 0 & $5(17.2)$ & 0 \\
\hline Asthenia & $3(5.1)$ & 0 & $4(13.8)$ & $1(3.4)$ \\
\hline Chest discomfort & $1(1.7)$ & 0 & $3(10.3)$ & 0 \\
\hline \multicolumn{5}{|l|}{ Immune disorders } \\
\hline Hypersensitivity & $4(6.8)$ & $2(3.4)$ & $3(10.3)$ & 0 \\
\hline \multicolumn{5}{|l|}{ Infections and infestations } \\
\hline Nasopharyngitis & $6(10.2)$ & 0 & $3(10.3)$ & 0 \\
\hline Paronychia & $6(10.2)$ & 0 & $2(6.9)$ & 0 \\
\hline \multicolumn{5}{|l|}{ Investigations } \\
\hline White blood cell count decreased & 0 & 0 & $3(10.3)$ & $2(6.9)$ \\
\hline \multicolumn{5}{|l|}{ Metabolism and nutritional disorders } \\
\hline Decreased appetite & $13(22.0)$ & $1(1.7)$ & $7(24.1)$ & $1(3.4)$ \\
\hline Hypokalaemia & $6(10.2)$ & $3(5.1)$ & $3(10.3)$ & $1(3.4)$ \\
\hline Hypomagnesemia & $6(10.2)$ & $1(1.7)$ & $2(6.9)$ & 0 \\
\hline \multicolumn{5}{|c|}{ Musculoskeletal and connective tissue disorders } \\
\hline Myalgia & 11 (18.6) & 0 & $6(20.7)$ & $1(3.4)$ \\
\hline Pain in extremity & $10(16.9)$ & $1(1.7)$ & $5(17.2)$ & 0 \\
\hline Bone pain & $6(10.2)$ & 0 & $5(17.2)$ & 0 \\
\hline Arthralgia & $6(10.2)$ & 0 & $4(13.8)$ & 0 \\
\hline Back pain & $5(8.5)$ & 0 & $3(10.3)$ & $1(3.4)$ \\
\hline \multicolumn{5}{|c|}{ Neoplasms benign, malignant and unspecified (including cysts and polyps) } \\
\hline Tumor pain & $2(3.4)$ & 0 & $3(10.3)$ & 0 \\
\hline \multicolumn{5}{|l|}{ Nervous system disorders } \\
\hline Polyneuropathy & $16(27.1)$ & $4(6.8)$ & $9(31.0)$ & $2(6.9)$ \\
\hline Paresthesia & $7(11.9)$ & 0 & $9(31.0)$ & 0 \\
\hline Dizziness & $8(13.6)$ & 0 & $6(20.7)$ & 0 \\
\hline Headache & $7(11.9)$ & 0 & $4(13.8)$ & 0 \\
\hline Dysgeusia & $5(8.5)$ & 0 & $5(17.2)$ & 0 \\
\hline Peripheral sensory neuropathy & 0 & 0 & $3(10.3)$ & 0 \\
\hline \multicolumn{5}{|l|}{ Psychiatric disorders } \\
\hline Insomnia & $7(11.9)$ & 0 & $5(17.2)$ & 0 \\
\hline \multicolumn{5}{|c|}{ Respiratory, thoracic and mediastinal disorders } \\
\hline Cough & $12(20.3)$ & 0 & $11(37.9)$ & 0 \\
\hline Dyspnea & $12(20.3)$ & $1(1.7)$ & $10(34.5)$ & $1(3.4)$ \\
\hline
\end{tabular}


Table 4 (continued)

\begin{tabular}{|c|c|c|c|c|}
\hline \multirow[b]{2}{*}{ Adverse Events (AEs), n (\%) } & \multicolumn{2}{|c|}{ BTH1677 $(N=59)$} & \multicolumn{2}{|c|}{ Control $(N=29)$} \\
\hline & All AEs & Grade 3 or Grade 4 AEs & All AEs & Grade 3 or Grade 4 AEs \\
\hline Dysphonia & $6(10.2)$ & $1(1.7)$ & $6(20.7)$ & 0 \\
\hline Epistaxis & 7 (11.9) & 0 & $5(17.2)$ & 0 \\
\hline Pleural effusion & $7(11.9)$ & $3(5.1)$ & $3(10.3)$ & 0 \\
\hline Oropharyngeal pain & $3(5.1)$ & 0 & $3(10.3)$ & 0 \\
\hline \multicolumn{5}{|c|}{ Skin and subcutaneous tissue disorders } \\
\hline Rash & $28(47.5)$ & $2(3.4)$ & $19(65.5)$ & $3(10.3)$ \\
\hline Alopecia & $22(37.3)$ & 0 & $13(44.8)$ & 0 \\
\hline Dermatitis & $12(20.3)$ & 0 & $5(17.2)$ & 0 \\
\hline Pruritus & $9(15.3)$ & $1(1.7)$ & $4(13.8)$ & $1(3.4)$ \\
\hline Skin fissures & $11(18.6)$ & 0 & $2(6.9)$ & 0 \\
\hline Dry skin & $6(10.2)$ & 0 & $3(10.3)$ & 0 \\
\hline
\end{tabular}

BTH1677 in combination with cetuximab, carboplatin, and paclitaxel numerically improved the ORR in patients with previously untreated, advanced NSCLC by $13 \%$ ( $p=0.2895$; central review) to $24 \%$ ( $p=0.0468$; investigator review) beyond the ORR observed in Control patients. No meaningful changes were observed in other tumorassociated assessments or survival. Subject numbers were small for time-to-event assessments and not all randomized subjects were included in the primary efficacy populations. Furthermore, large differences in the percentage of patients censored for some of these assessments in the investigator $(\sim 20 \%)$ vs central $(\sim 50 \%)$ reviews no doubt further clouded an ability to see consistent meaningful changes.

Table 5 Summary of BTH1677 pharmacokinetics parameters

\begin{tabular}{lll}
\hline Parameters & \multicolumn{2}{l}{ Geometric Mean $(\mathrm{CV} \%)$} \\
\cline { 2 - 3 } & \multicolumn{1}{l}{ BTH1677 } \\
\cline { 2 - 3 } & \multicolumn{1}{l}{ Cycle 1/Day 1 } & Cycle 3/Day 1 \\
\hline $\mathrm{N}$ & 52 & 36 \\
$\mathrm{AUC}_{0-\text { last }}(\mu \mathrm{g} \cdot \mathrm{hr} . / \mathrm{mL})$ & $605(55.3)$ & $396(38.1)$ \\
$\mathrm{AUC}_{0-24}(\mu \mathrm{g} \cdot \mathrm{hr} . \mathrm{mL})$ & $362(35.2)$ & $396(34.8)$ \\
$\mathrm{AUC}_{0-\infty}(\mu \mathrm{g} \bullet \mathrm{hr} . / \mathrm{mL})$ & $621(53.1)$ & $416(30.4)$ \\
$\mathrm{C}_{\max }(\mu \mathrm{g} / \mathrm{mL})$ & $44.3(34.9)$ & $47.8(37.3)$ \\
$\mathrm{CL}(\mathrm{L} / \mathrm{h})$ & $0.477(46.4)$ & $0.696(32.1)$ \\
$\mathrm{t}_{1 / 2}(\mathrm{hr})$ & $19.1(42.8)$ & $8.46(23.2)$ \\
$\mathrm{t}_{\max }(\mathrm{hr})^{*}$ & $2.25(1.97,4.33)$ & $2.40(1.93,4.17)$ \\
$\mathrm{V}_{\mathrm{ss}}(\mathrm{L})$ & $6.60(35.5)$ & $6.48(39.9)$ \\
\end{tabular}

$N$ number of patients, $C V$ coefficient of variation, $A U C_{(0-\text { last })}$ area under the plasma concentration-time curve from time 0 to the time of the last measurable concentration, $A U C_{0-24}$ area under the plasma concentrationtime curve from time 0 to $24 \mathrm{~h}, A U C_{0-\infty}$ area under the plasma concentration-time curve from time 0 to infinity, $C_{\max }$ maximum plasma concentration, $C L$ systemic clearance; $\mathrm{t}_{1 / 2}$, elimination half-life, $t_{\max }$ time of maximum concentration, $V_{s s}$ volume of distribution at steady-state

*Median (range)
The population enrolled in this study was similar to the large BMS099 study $(N=676)$ evaluating cetuximab and carboplatin/taxane vs carboplatin/taxane alone as first-line treatment in advanced NSCLC patients that were not selected for EGFR expression or KRAS gene status [13]. Our Control ORRs of $23.1 \%$ (both investigator and central reviews) compare similarly to the ORRs of $27.5 \%$ (investigator review) and $25.7 \%$ (central review) in the BMS099 cetuximab and carboplatin/taxane arm. In light of our Control ORR responding as expected, the improved $47.8 \%$ (investigator review) and $36.6 \%$ (central review) ORRs observed with the addition of BTH1677 to the backbone therapy does suggest further benefit from the addition of BTH1677. However, whether improved ORR will translate into benefit in more clinically relevant endpoints such as PFS or OS would require larger studies powered for such endpoints. Even in the large BMS099 study, improved ORR did not translate into improved PFS or OS. In the larger FLEX study $(N=1125)$, evaluating cetuximab and cisplatin/vinorelbine vs cisplatin/ vinorelbine alone as first-line treatment in selected EGFRexpressing advanced NSCLC patients [14], the slight improvement in ORR (36\% vs $29 \%$ ) was associated with a statistically significant improvement in OS, but the effect was very modest (11.3 vs 10.1 months; HR $0.871 ; p=0.044$ ).

Interestingly, our findings indicated that ABA level may be useful as a predictive biomarker for response to BTH1677. BTH1677 biomarker-positive patients exhibited better OS than biomarker-negative patients. However, no serum was available from Control patients for ABA analysis and, therefore, key comparisons of BTH1677 biomarker-positive and biomarker-negative responses to Control biomarker-positive and biomarker-negative responses could not be performed. Hence, the possibility that ABA level may be prognostic for better responders vs predictive of a BTH1677-specific effect cannot be ruled out. Given the critical role of ABA in facilitating the binding of BTH1677 to immune cells [18-22, 39-42] the former seems unlikely; however, controlled studies are needed to further assess the true contribution of $\mathrm{ABA}$ in 
response to BTH1677, as well as to refine the most appropriate $\mathrm{ABA}$ thresholds for defining biomarker-positive and biomarker-negative patients in the cancer population.

In terms of safety, BTH1677 combination therapy was well tolerated among patients, which was consistent with previous experience using BTH1677 in combination with cetuximab in mCRC patients [34-37]. Overall, most AEs were mild or moderate in severity. Only skin fissures occurred at a $10 \%$ greater incidence in the BTH1677 arm than in the Control $\operatorname{arm}(18.6 \%$ vs $6.9 \%)$.

PK parameters were consistent with those previously observed in healthy volunteers [34], suggesting that neither cetuximab nor the carboplatin and paclitaxel therapy affected the PK of BTH1677.

In conclusion, BTH1677 in combination with cetuximab and concomitant carboplatin and paclitaxel improved ORR and was well tolerated in patients with previously untreated, advanced NSCLC. At the time this study was initiated, cetuximab was undergoing regulatory review for first-line use in late-stage NSCLC patients, but ultimately never received approval. Hence, although the treatment regimen used here will not proceed to further evaluation, the results of this study support the concept of improved efficacy with the addition of BTH1677 to antibody therapy. The NSCLC study run in parallel with this study, that evaluated BTH1677 combined with bevacizumab/carboplatin/paclitaxel in non-squamous late-stage NSCLC patients, also demonstrated promising results [43], and a NSCLC study of BTH1677 in combination with pembrolizumab is ongoing (ClinicalTrials.gov NCT03003468). This novel therapeutic also continues to be investigated in combination with antibody therapies in additional oncology clinical trials that also include further investigation into the possible role of $\mathrm{ABA}$ as a predictive biomarker for response to BTH1677.

\begin{abstract}
Acknowledgements The authors would like to acknowledge additional investigators of the BTH1677 NSCLC Study Team including Oliver Schmalz, MD, HELIOS Klinikum Wuppertal Medizinische, Wuppertal, Germany; Gautam Jha, MD, University of Minnesota, Minneapolis, MN, USA; Zhonglin Hao, MD, Georgia Regents University, Augusta, GA, USA; David Watkins, MD, Allison Cancer Center, Midland, TX, USA; Neil Senzer, MD, Mary Crowley Medical Research Center, Dallas, TX; and Sang Huh, MD, Providence Medical Group, Terre Haute, IN, USA. The authors would also like to acknowledge Biothera Pharmaceuticals Inc. employees Jose Iglesias, MD, Richard Huhn, MD, and Mable Ma, $\mathrm{PhD}$ for manuscript review; Corina Taitt, MD, for data cleaning and analysis; Blaine Rathmann, BS and Katie Ertelt, BS for assistance in assaying beta glucan levels in serum samples; and Mary Antonysomy, $\mathrm{PhD}$, Diane McMurry, BS, Steven Leonardo, PhD, and Lindsay Wurst, BA for assistance in assaying anti-beta-glucan antibody levels in serum samples. Also acknowledged are Susan Goebel for assistance in statistical programming, VirtualScopics, Inc. for independent central radiology reviews and analysis and Chastity Bradley, $\mathrm{PhD}$ and Molly Nixon, $\mathrm{PhD}$ of Synchrogenix for medical writing assistance.
\end{abstract}

\section{Compliance with ethical standards}

Conflict of interest At the time this study was performed, Nandita Bose, Michele Gargano, Keith Gorden, Jamie Lowe, Paulette Mattson, Myra Patchen, and Richard Walsh were employed in leadership roles at Biothera Pharmaceuticals Inc. and owned stock/stock options in Biothera Pharmaceuticals Inc. Martin Beliveau and JF Marier were compensated by Biothera for pharmacokinetic analysis assistance and $\mathrm{J}$ Richard Trout was compensated by Biothera for statistical analysis assistance. The remaining authors declare no conflict of interest.

Funding This work was supported by Biothera Pharmaceuticals Inc.

Ethical approval This Phase II study was conducted in full accordance with the Good Clinical Practice: Consolidated Guideline approved by the International Conference on Harmonisation and all other applicable national and local laws/regulations. All study materials were approved by the governing ethics committee or institutional review board at each site.

Informed consent Informed consent was obtained from all individual patients included in the study.

Open Access This article is distributed under the terms of the Creative Commons Attribution 4.0 International License (http:// creativecommons.org/licenses/by/4.0/), which permits unrestricted use, distribution, and reproduction in any medium, provided you give appropriate credit to the original author(s) and the source, provide a link to the Creative Commons license, and indicate if changes were made.

\section{References}

1. American Society Society (2015) Lung Cancer (Non-Small Cell) http://www.cancer.org/cancer/lungcancer-nonsmallcell/detailedguide/non-small-cell-lung-cancer-key-statistics. Accessed 15 September 2016

2. Peters S, Adjei AA, Gridelli C, Reck M, Kerr K, Felip E on behalf of the ESMO Guidelines Working Group (2012) Metastatic non-smallcell lung cancer (NSCLC): ESMO Clinical Practice Guidelines for diagnosis, treatment and follow-up. Ann Oncol 23 Suppl 7:vii56-vii64

3. Azzoli CG, Temin S, Aliff T, Baker S Jr, Brahmer J, Johnson DH, Laskin JL, Masters G, Milton D, Nordquist L, Pao W, Pfister DG, Piantadosi S, Schiller JH, Smith R, Smith TJ, Strawn JR, Trent D, Giaccone G, American Society of Clinical Oncology (2011) 2011 focused update of 2009 American Society of Clinical Oncology clinical practice guideline update on chemotherapy for stage IV non-small-cell lung cancer. J Clin Oncol 29:3825-3831

4. National Comprehensive Cancer Network (2016) NCCN Guidelines for Patients with Non-Small Cell Lung Cancer https://www.ncen.org/store/login/login.aspx?ReturnURL= https://www.nccn.org/professionals/physician_gls/pdf/nscl.pdf. Accessed 15 September 2016

5. Besse B, Adjei A, Baas P, Meldgaard P, Nicholson M, Paz-Ares L, Reck M, Smit EF, Syrigos K, Stahel R, Felip E, Peters S, Panel Members, ESMO (2014) 2nd ESMO consensus conference on lung cancer: non-small-cell lung cancer first-line/second and further lines of treatment in advanced disease. Ann Oncol 25:1475-1484

6. Avastin ${ }^{\circledR}$ (bevacizumab) Prescribing Information (2015) Genetech. Inc, San Francisco

7. Erbitux® (cetuximab) Prescribing Information (2016) Eli Lilly and Company: Indianapolis

8. Portrazza ${ }^{\mathrm{TM}}$ (necitumumab) Prescribing Information (2015) Eli Lilly and Company: Indianapolis 
9. Keytruda ${ }^{\circledR}$ (pembrolizumab) Prescribing Information (2014) Merck \& Co. Whitehouse Station, Inc.

10. Cyramza ${ }^{\circledR}$ (ramucirumab) Prescribing Information (2014) Eli Lilly and Company: Indianapolis

11. Opdivo ${ }^{\circledR}$ (nivolumab) injection Prescribing Information (2017) Bristol-Myers Squibb Company: Princteon

12. Tecentriq ${ }^{\circledR}$ (atezolizumab) Prescribing Information (2016) Genentech. Inc, San Francisco

13. Lynch TJ, Patel T, Dreisbach L, McCleod M, Heim WJ, Hermann RC, Paschold E, Iannotti NO, Dakhil S, Gorton S, Pautret V, Weber MR, Woytowitz D (2010) Cetuximab and first-line taxane/ carboplatin chemotherapy in advanced non-small-cell lung cancer: results of the randomized multicenter phase III trial BMS099. J Clin Oncol 28:911-917

14. Pirker R, Pereira JR, Szczesna A, von Pawel J, Krzakowski M, Ramlau R, Vynnychenko I, Park K, Yu CT, Ganul V, Roh JK, Bajetta E, O'Byrne K, de Marinis F, Eberhardt W, Goddemeier T, Emig M, Gatzemeier U, FLEX Study Team (2009) Cetuximab plus chemotherapy in patients with advanced non-small-cell lung cancer (FLEX): an open-label randomised phase III trial. Lancet 373: $1525-1531$

15. Bacic A, Fincher GB, Stone BA (2009) Chemistry, biochemistry, and biology of $(1 \rightarrow 3)-\beta$-glucans and related polysaccharides. Elsevier, New York

16. Zhou Z, Han Z, Zeng Y, Zhang M, Cui Y, Xu L, Zhang L (2014) Chinese FDA approved fungal glycan-based drugs: an overview of structures, mechanisms and clinical related studies. Transl Med 4:141

17. Kidd PM (2000) The use of mushroom glucans and proteoglycans in cancer treatment. Altern Med Rev 5:4-27

18. Chan AS, Jonas A, Qui X, Ottoson NR, Walsh RM, Gorden KB, Harrison B, Maimonis PJ, Leonardo SM, Ertelt KE, Danielson ME, Michel KS, Nelson M, Graff JR, Patchen ML, Bose N (2016) Imprime PGG-mediated anti-cancer immune activation requires immune complex formation. PLoS One 11:e0165909

19. Bose N, Chan AS, Guerrero F, Maristany CM, Qiu X, Walsh RM, Ertelt KE, Jonas AB, Gorden KB, Dudney CM, Wurst LR, Danielson ME, Elmasry N, Magee AS, Patchen ML, Vasilakos JP (2013) Binding of soluble yeast beta-glucan to human neutrophils and monocytes is complement-dependent. Front Immunol 4:230

20. Chan ASH, Qiu X, Bykowski Jonas A, Patchen ML, Bose N (2014) Imprime PGG, a yeast beta glucan immunomodulator, has the potential to repolarize human monocyte-derived M2 macrophages to M1 phenotype. J Immunother Cancer 2(Suppl 3):191

21. Chan ASH, Qiu X, Jonas A, Kangas T, Ottoson NR, Bose N (2015) Imprime PGG modulates the function of monocyte-derived M2 macrophages and dendritic cells to drive $\mathrm{T}$ cell expansion. Cancer Res 75(Suppl 15):LB225

22. Fraser K, Ottoson N, Qiu X, Chan ASH, Jonas A, Kangas T, Graff J, Bose N (2016) Imprime PGG modulates the myeloid component of the tumor microenvironment to coordinate an anti-tumor immune response. Cancer Res 76(Suppl 3):A02

23. Leonardo SM, Gorden K, Fulton R, Wurst L (2015) Imprime PGG decreases regulatory $\mathrm{T}$ cell suppression and enhances $\mathrm{T}$ cell proliferation and differentiation revealing additional mechanisms for its anti-tumor activity. Cancer Res 75(Suppl 15):5034

24. Bose N, Fulton R, Chan A, Leonardo S, Fraser K, Jonas A, Ottoson N, Qiu X, Gorden K, Graff J (2015) Imprime PGG, a yeast-derived Pathogen-associated molecular pattern (PAMP), drives a coordinated anti-cancer immmune attack (abstract). Symposia on Cancer Research: Emerging Concepts in Host Response to Cancer, Houston

25. Bose N, Chan ASH, Bykowski Jonas A, Qiu X, Ottoson NR, Kangas T, Graff JR (2015) Imprime PGG treatment elicits a coordinated antitumor immune response that triggers enhanced expression of PD-L1 on tumor cells as well as monocyte-derived macrophages and dendritic cells. Cancer Res 75 (Suppl 15):LB-228
26. Fulton RB, Leonardo SM, Michel KS, Danielson ME, Gorden K, Graff JR (2016) Imprime PGG, a soluble beta-glucan, binds to and activate dendritic cells resulting in enhanced $\mathrm{T}$ cell priming, expansion, and cytokine production. Cancer Immunol Res 4:B019

27. Li B, Allendorf DJ, Hansen R, Marroquin J, Ding C, Cramer DE, Yan J (2006) Yeast beta-glucan amplifies phagocyte killing of iC3bopsonized tumor cells via complement receptor 3-Sykphosphatidylinositol 3-kinase pathway. J Immunol 177:1661-1669

28. Li B, Allendorf DJ, Hansen R, Marroquin J, Ding C, Cramer DE, Harris CL, Yan J (2007) Combined yeast \{beta\}-glucan and antitumor monoclonal antibody therapy requires C5a-mediated neutrophil chemotaxis via regulation of decay-accelerating factor CD55. Cancer Res 67:7421-7430

29. Qi C, Cai Y, Gunn L, Ding C, Li B, Kloecker G, Qian K, Vasilakos J, Saijo S, Iwakura Y, Yannelli JR, Yan J (2011) Differential pathways regulating innate and adaptive antitumor immune responses by particulate and soluble yeast-derived beta-glucans. Blood 117: 6825-6836

30. Salvador C, Li B, Hansen R, Cramer DE, Kong M, Yan J (2008) Yeast-derived beta-glucan augments the therapeutic efficacy mediated by anti-vascular endothelial growth factor monoclonal antibody in human carcinoma xenograft models. Clin Cancer Res 14: $1239-1247$

31. Zhong W, Hansen R, Li B, Cai Y, Salvador C, Moore GD, Yan J (2009) Effect of yeast-derived beta-glucan in conjunction with bevacizumab for the treatment of human lung adenocarcinoma in subcutaneous and orthotopic xenograft models. J Immunother 32: 703-712

32. Jonas $\mathrm{A}$, Chan $\mathrm{A}$, Ottoson $\mathrm{N}$ et al (2016) Imprime PGG drives adaptive immune resistance within the tumor microenvironment by modulating the myeloid compartment and enhances the efficacy of anti-PD1 antibody in vivo (abstract). Annual Meeting of the American Association for Cancer Research, New Orleans

33. Fraser $\mathrm{K}$, Chan A, Fulton R, Leonardo S, Jonas A, Qiu X, Ottoson N, Kangas T, Gorden K, Graff J, Bose N (2016) Imprime PGG triggers PD-L1 expression on tumor and myeloid cells and prevents tumor establishment in combination with anti-PD-L1 treatment in vivo (abstract). Annual Meeting of the American Association for Cancer Research, New Orleans

34. Halstenson C, Shamp T, Gargano M, Walsh RM, Patchen ML (2016) Two randomized, double-blind, placebo-controlled, doseescalation phase 1 studies evaluating BTH1677, a 1, 3-1,6 beta glucan pathogen associated molecular pattern, in healthy volunteer subjects. Investig New Drugs 34:202-215

35. Tamayo MB, Cornelio GH, Bautista JB, Flores ML, Tioleco PS, Vasilakos JP, Marsh LM, Walsh RM, Gargano MA, Patchen ML (2010) Safety, pharmacokinetics (PK), and efficacy of Imprime PGG plus cetuximab (cetux) with and without irinotecan (irino) in advanced metastatic colorectal cancer (mCRC) patients (abstract). Ann Oncol 21(Suppl 8):4584

36. Tamayo MB, Cornelio GH, Bautista JB, Flores ML, Tioleco PS, Kurman MR, Vasilakos JV, Marsh LM, Gargano MA, Patchen ML (2010) Safety and efficacy of Imprime PGG plus cetuximab with irinotecan and without irinotecan in patients with advanced colorectal cancer (CRC): a phase $1 \mathrm{~b} / 2$ study with KRAS subpopulation analysis (abstract). Ann Oncol 21(Suppl 6):PD0009

37. Cornelio G, Tamayo M, Flores ML, Bautista JB, Tioleco PS, Gargano MA, Kurman MR, Walsh RM, Beliveau M, Marier J-F, Patchen ML (2016) A phase Ib/II study evaluating the safety, pharmacokinetics, and efficacy of BTH1677 in combination with cetuximab with and without irinotecan in patients with advanced metastatic colorectal cancer. Colorectal Cancer 5:95-108

38. Chen TT, Ng TH (1998) Optimal flexible designs in phase II clinical trials. Stat Med 17:2301-2312

39. Bose N, Antonysamy MA, Patchen ML, Lowe JR, Mattson P, Gargano MA, Gorden K, Leonardo S, Walsh R, Qiu X, Ottoson 
N, Ertelt K, Wurst L, Rathmann B, Nelson M, McMurray D, Chan ASH, Jonas A, Huhn R, Thomas M, Sadjadian P, Schneller F (2014) Endogenous anti-beta-glucan antibodies as a potential predictive biomarker for clinical response to Imprime PGG immunotherapy in non-small cell lung cancer (NSCLC) patients. J Clin Oncol 13(15S):3045

40. Bose N, Jonas A, Qiu X, Chan Z, Ottoson N, Graff J (2015) Imprime PGG treatment enhances antibody-dependent cellular phagocytosis (ADCP) of tumor cells by monocyte-derived macrophages (abstract). AACR the Inaugural International Cancer Immunotherapy Conference: Translating Science into Survival, New York

41. Jonas A, Qiu X, Chan A, McMurray D, Bose N (2015) Imprime PGG, a yeast beta-glucan immunomodulator, can engage fc gamma receptor $(\mathrm{FcgR})$ in addition to complement receptor 3 (CR3) on human neutrophils and monocytes (abstract). Keystone symposium on tumor immunology. Multidisciplinary Science Driving Combination Therapy, Banff, Alberta

42. Leonardo SM, Fulton RB, Wurst LR, Gorden KB, Bykowski Jonas A, Qui X, Chan ASH, Graff JR (2016) Imprime PGG binds to neutrophils through complement, fc, and dectin-1 receptors, priming these cells for enhanced ROS production and tumor cell cytotoxicity. Cancer Immunol Res 4:A160

43. Engel-Riedel WS, Schneller F, Wolf M, Schuette W, Lowe J, Mattson P, Gargano M, Patchen ML, Bose N, Huhn RD, Braun A (2014) Imprime PGG, a novel immune modulator, in the 1st line treatment of stage IV NSCLC: results from a randomized, controlled, multicenter phase 2 study (abstract). Ann Oncol 25(Suppl 4):LBA32 